\title{
Severe Hyponatremia and Hypocalcemia in Gitelman Syndrome: A Case Report
}

\author{
Mansoor C. Abdulla ${ }^{a}$,, Jemshad Alungal ${ }^{a}$, Sameer Ahammed Karumannil ${ }^{\mathrm{a}}$, Ram Narayan
}

\begin{abstract}
Gitelman syndrome (GS) is a recessive salt-losing tubulopathy due to a mutation of genes encoding the sodium chloride cotransporters and magnesium channels in the thiazide-sensitive segments of the distal convoluted tubule. In this paper we describe a 69-yearold lady with GS who presented with severe hyponatremia and hypocalcemia which are very rare complications associated with this syndrome. We are discussing the mechanisms involved in the development of these rare manifestations in this case report.
\end{abstract}

Keywords: Gitelman syndrome; Hyponatremia; Hypocalcemia

\section{Introduction}

Gitelman syndrome (GS) is caused by inactivating mutations in the gene for the sodium chloride channel (thiazide-sensitive NCC) of the distal convoluted tubule, called SLC12A3 [1]. Usual age of presentation is late childhood or early adolescence. GS is characterized by hypokalemia, hypomagnesemia, metabolic alkalosis and low urinary calcium excretion [2]. They also have normal serum sodium and calcium, hyperuricemia and inappropriately high urinary potassium, magnesium and chloride usually [3]. In this paper we present a case of GS with severe hyponatremia and hypocalcemia which was hardly described in the literature.

\section{Case Report}

A 69-year-old lady was presented with fatigue for 1 week.

Manuscript accepted for publication February 20, 2014

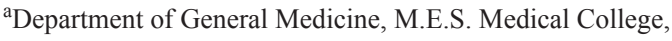
Perinthalmanna, Kerala 679338, India

${ }^{\mathrm{b}}$ Corresponding author: Mansoor C. Abdulla, Department of General Medicine, M.E.S. Medical College, Perinthalmanna, Kerala 679338, India.Email: drcamans@gmail.com

doi: http://dx.doi.org/10.14740/wjnu149w
She did not give any history of diabetes mellitus or hypertension and was not on any drugs. On examination she was pale and the blood pressure was $130 / 80 \mathrm{~mm} \mathrm{Hg}$. She appeared adequately hydrated on clinical examination and examination of respiratory, cardiovascular, neurological systems and abdomen were unremarkable. Investigations showed hemoglobin $10.9 \mathrm{~g} / \mathrm{dL}$ (microcytic hypochromic), total WBC count $9,600 / \mu \mathrm{L}$, platelet count $2.4 \times 10^{9} / \mathrm{L}$, ESR $65 \mathrm{~mm}$ in $1 \mathrm{~h}$. Urinalysis showed $2-4$ leucocytes/high power field. There was no albuminuria or visible RBC in the urine. Chest $\mathrm{X}$-ray was normal and electrocardiogram showed $\mathrm{U}$ waves and flattened $\mathrm{T}$ waves. Her biochemical parameters revealed RBS $127 \mathrm{mg} \%$, urea $27 \mathrm{mg} / \mathrm{dL}$, creatinine $1.1 \mathrm{mg} / \mathrm{dL}$ and uric acid $2.0 \mathrm{mg} \%$. Tests on liver function, thyroid function and serum cortisol showed normal results. The serum and urinary electrolytes, arterial blood gas analyses are shown in Table 1. Urine culture was sterile and ultrasonography of abdomen was normal. The trans-tubular potassium gradient was seven. Since the patient had hypokalemia with high trans-tubular potassium gradient, metabolic alkalosis, normal blood pressure, hypomagnesemia, high urinary chloride and hypocalciuria, a diagnosis of GS was made. In addition to the usual electrolyte abnormalities she also had severe hyponatremia, hypocalcemia and hypouricemia.

She was treated with parenteral potassium, calcium and magnesium initially along with spironolactone. The sodium level improved with fluid restriction and hypertonic saline, and electrolytes showed improvement after 7 days. She was discharged with advice to continue oral potassium, calcium and magnesium supplements.

\section{Discussion}

Evaluating a patient with dyselectrolytemia is an interesting academic exercise for the physician especially if some unusual complications are encountered. The combination of hypokalemic metabolic alkalosis with hypomagnesemia and hypocalcemia are the characteristic electrolyte abnormalities described with GS. Serum sodium and calcium are usually normal in patients with GS. In this paper we describe a patient who had the classical features of GS with severe hypo- 
Table 1. Serum and Urinary Electrolytes, Arterial Blood Gas Analysis

\begin{tabular}{|c|c|c|}
\hline & Patient value & Normal range \\
\hline \multicolumn{3}{|l|}{ Serum $(\mathrm{mmol} / \mathrm{L})$} \\
\hline Sodium & 110 & $135-145$ \\
\hline Potassium & 1.8 & $3.5-5.0$ \\
\hline Bicarbonate & 32 & $22-26$ \\
\hline Calcium & 1.475 & $2.2-2.67$ \\
\hline Phosphorus & 1.35 & $0.8-1.5$ \\
\hline Magnesium & 0.29 & $0.7-1.1$ \\
\hline Measured serum osmolality (mOsm/kg) & 235 & $285-295$ \\
\hline Urine osmolality (mOsm/kg) & 234 & $80-1,350$ \\
\hline \multicolumn{3}{|l|}{$24 \mathrm{~h}$ urine analysis } \\
\hline Sodium (mmol/24 h) & 210 & Variable \\
\hline Potassium (mmol/24 h) & 36 & Variable \\
\hline Urinary chloride (mmol/L) & 87 & Variable \\
\hline Urinary calcium creatinine ratio & 0.079 & Variable \\
\hline \multicolumn{3}{|l|}{ Arterial blood gas analysis } \\
\hline $\mathrm{pH}$ & 7.59 & $7.35-7.45$ \\
\hline $\mathrm{PCO}_{2}(\mathrm{~mm} \mathrm{Hg})$ & 31 & $35-45$ \\
\hline $\mathrm{PO}_{2}(\mathrm{~mm} \mathrm{Hg})$ & 64 & $80-105$ \\
\hline $\mathrm{HCO}_{3}(\mathrm{mEq} / \mathrm{L})$ & 30 & $22-26$ \\
\hline
\end{tabular}

natremia and hypocalcemia.

Hyponatremia was described with GS for the first time by Schepkens et al in 2001 in two patients [3]. The phenotype of GS is identical to that with the chronic use of thiazide diuretics [1]. Thiazide induced hyponatremia has features similar to that of SIADH [4]. Thiazides are "Saluretic", whereas frusemide causes water diuresis, "aquaretics". Various mechanisms have been attributed to thiazide induced hyponatremia. Thiazide induced hyponatremia occurs when the intake of free water is greater than the amount the kidneys can excrete. In subjects with a moderate impairment of freewater excretion, a thiazide will cause hyponatremia if fluid intake is excessive. Hyponatremia can even appear in those with more serious impairment of free-water excretion with ordinary fluid intake [5]. In patients with GS a similar mechanism may result in hyponatremia which resembles SIADH. Thus GS patients are prone to developing hyponatremia in a manner similar to that seen with thiazide diuretics. But hyponatremia is unusual in GS patients since they achieve a balance between water intake and free-water excretion under normal circumstances. Our patient under study had a normal volume status clinically, hypoosmolar hyponatremia, hypouricemia with an inappropriately high urinary osmolality and sodium, all consistent with SIADH. So the probable cause for hyponatremia in our patient is likely to be as discussed above.

Patients with GS have significant hypomagnesemia. Chronic hypomagnesemia is closely associated with hypocalcemia, which is caused by impaired parathyroid hormone (PTH) secretion or the refractoriness of bone and renal tubules to PTH [6]. In general, PTH-induced release of calcium from bone is substantially impaired when the plasma magnesium concentration falls below $0.8 \mathrm{mEq} / \mathrm{L}(1 \mathrm{mg} / \mathrm{dL}$ or $0.4 \mathrm{mmol} / \mathrm{L}$ ). In comparison, it appears that more severe hypomagnesemia [7] occurs only when there is diminished PTH secretion.

Pantanetti et al [8] and Nakamura et al [9] describe two patients with GS in whom hypocalcemia developed due to hypomagnesemia. The combination of two rare complications, namely hyponatremia and hypocalcemia, in our case 
makes this a unique case of GS and throws open scope for more study and research.

\section{Sources of Support}

None.

\section{Conflicts of Interest}

None.

\section{References}

1. Simon DB, Nelson-Williams C, Bia MJ, Ellison D, Karet FE, Molina AM, Vaara I, et al. Gitelman's variant of Bartter's syndrome, inherited hypokalaemic alkalosis, is caused by mutations in the thiazide-sensitive NaCl cotransporter. Nat Genet. 1996;12(1):24-30.

2. Jang HR, Lee JW, Oh YK, Na KY, Joo KW, Jeon US, Cheong HI, et al. From bench to bedside: diagnosis of Gitelman's syndrome -- defect of sodium-chloride cotransporter in renal tissue. Kidney Int. 2006;70(4):813-
817.

3. Schepkens H, Stubbe J, Hoeben H, Vanholder R, Lameire N. Severe hyponatraemia and hypouricaemia in Gitelman's syndrome. Nephrol Dial Transplant. 2001;16(11):2250-2252.

4. Fichman MP, Vorherr H, Kleeman CR, Telfer N. Diuretic-induced hyponatremia. Ann Intern Med. 1971;75(6):853-863.

5. Mann SJ. The silent epidemic of thiazide-induced hyponatremia. J Clin Hypertens (Greenwich). 2008;10(6):477-484.

6. Yamamoto M, Yamaguchi T, Yamauchi M, Yano S, Sugimoto T. Acute-onset hypomagnesemia-induced hypocalcemia caused by the refractoriness of bones and renal tubules to parathyroid hormone. J Bone Miner Metab. 2011;29(6):752-755.

7. Agus ZS. Hypomagnesemia. J Am Soc Nephrol. 1999;10(7):1616-1622.

8. Pantanetti P, Arnaldi G, Balercia G, Mantero F, Giacchetti G. Severe hypomagnesaemia-induced hypocalcaemia in a patient with Gitelman's syndrome. Clin Endocrinol (Oxf). 2002;56(3):413-418.

9. Nakamura A, Shimizu C, Nagai S, Taniguchi S, Umetsu $\mathrm{M}$, Atsumi T, Yoshioka N, et al. A rare case of Gitelman's syndrome presenting with hypocalcemia and osteopenia. J Endocrinol Invest. 2005;28(5):464-468. 